IADIS International Journal on WWW/Internet

Vol. 19, No. 1, pp. 1-16

ISSN: $1645-7641$

\title{
THE SOCIAL AFFORDANCES OF SOCIAL MEDIA FOR INFORMAL LEARNERS
}

\author{
Maryam Meshari Almukhaylid, Salah Kabanda and Nawal Nasser Al-Haidari \\ University of Cape Town. Cape Town, South Africa
}

\begin{abstract}
The increasing use of social media for learning purposes, especially during the COVID-19 pandemic, has opened new horizons for self-learning. Although several affordances are associated with social media use, there remains limited understanding of the social affordance's users enjoy from social media, specifically, users engaged in informal learning - a free-choice learning option where learners participate in activities voluntarily. Being aware of these social affordances can improve our understanding on how social media users learn informally as they draw upon those affordances. This study identifies the social affordances of social media when presented as an informal learning tool to learners; and in so doing, seeks to respond to the question What are the social affordances of social media tools in an informal learning context?

Following a descriptive systematic literature review synthesis as a methodological approach, the literature on social media and informal learning from an information system (IS) perspective were identified and analyzed to identify the social affordances. The findings show thirteen social affordances which online users enjoy in informal learning context when using social media. Given that social media was not designed for learning purposes, these findings contribute towards the discussion of social media as a learning tool by providing a descriptive contribution on the social affordances enabled by these platforms.
\end{abstract}

\section{KEYWORDS}

Affordances, Social Affordances, Social Media, Informal Learning

\section{INTRODUCTION}

Individuals are now increasingly in charge of knowledge creation and the sharing of it (Majchrzak, Faraj, Kane, \& Azad, 2013). Online platforms give users opportunities to learn anytime and wherever they are. Social media provides an informal learning environments where people engage and learn socially with others to help them understand new ideas (Conner, 2012). Informal learning is not organized learning and it usually occurs outside of educational institutions (Garcia, Elbeltagi, Dungay, \& Hardaker, 2015; Hsi, 2015; Lay Shi, Siew Ming, \& Noorizah Mohd, 2018). Informal learning through social media has helped learners to 
IADIS International Journal on WWW/Internet

overcome many of the challenges and barriers present in formal learning settings. This type of learning provides an opportunity to support the development of learner competencies and skills (Blaschke, 2014).

Learning is a mechanism by which individuals in society gain knowledge, facilitate change, and adapt to the context of any given situation (Aramo-Immonen, Karkkainen, Jussila, Joel-Edgar, \& Huhtamaki, 2016). Learning is a social process which cannot occur without cultural and community influences (Bagarukayo, Ssentamu, Mayisela, \& Brown, 2016). There are three main contexts in which learning can occur, namely formal, informal, and non-formal. Formal learning usually takes place in educational institutions that offer formal certification or degrees (Betul, 2016), whereas informal learning is not organized and usually occurs outside of educational institutions (Garcia et al., 2015; Hsi, 2015; Lay Shi et al., 2018). Non-formal learning is a midway between formal and informal, and it is separated from the established formal system and other more structured forms of learning (Klomsri, Grebäck, \& Tedre, 2013; Palmieri \& Giglio, 2015). This study focuses on informal learning a free-choice learning option where learners participate in activities voluntarily (Hsi, 2015). In Informal learning actors play a relevant role as content creators where they not only consume content, but generate and share it for learning purposes (Ocaña, Mejía, Larrea, Analuisa, \& Freire, 2021). Informal learning can occur either with or without using social media platforms (Genden, 2018).

Several studies such as Hamat and Abu Hassan (2019), Tallent (2014), Osborne (2014), and Baruh and Watson (2014) have highlighted social media's value for building and maintaining relationships with a variety of stakeholders in informal learning environments, thereby creating a space for continuous professional development and empowering people in their search for information. A prominent perspective within information systems regarding how to understand this relationship, between the technology (social media) and the user in the informal learning context, is through the study of affordances (Anderson \& Robey, 2017; Stendal, Thapa, \& Lanamäki, 2016; Volkoff \& Strong, 2017). Seven new learning affordances have opened up by new media: ubiquitous learning, active knowledge production, multimodal knowledge representations, recursive feedback, collaborative intelligence, metacognitive reflection and differentiated learning (Kalantzis \& Cope, 2015).

Social media provides a variety of affordances that help learners to achieve their goal. However, social media was not designed for learning purposes (McCarthy, 2015). Thus, learners need to repurpose social media for these informal learning activities to meet their needs. They need to discover and perceive as many of the social media affordances as they can. This is important bearing in mind that not all informal learners who use social media as tools for their learning have the same knowledge of the social media affordances they can tap into. By being aware of the affordances, informal learners would be more equipped to use social media tools effectively to accomplish their learning goals (Y. Li, 2013). Yet, researchers have not paid much attention to the social affordances of technology especially in the field of informal learning and social media; and are therefore unable to provide an explanation of how the social construction of technology impacts the practices afforded by that environment (Fayard \& Weeks, 2014). An understanding of the specific affordances will further our understanding of users' activities and their relationships with social media (Pozzi, Pigni, \& Vitari, 2014; Van Osch \& Mendelson, 2011). Considering this background and the limited work done on informal learning (Aramo-Immonen et al., 2016; Kanwar, Balasubramanian, \& Umar, 2013; Klomsri et al., 2013; Sangrà \& Wheeler, 2013; Yakin \& Gencel, 2013), this study seeks to identify the social affordances of social media as an informal learning tool for learners by responding to the question: What are the social affordances of social media tools in an informal learning context? 
The paper is structured as follows: Section 2 presents the related work on social affordances. This is followed by a section on the research methodology. Section 4 details the findings and discussion of those findings. Finally, Section 5 concludes the study and provides directions for future research.

\section{RELATED WORK}

The concept of affordance is multivalent. Originally developed in the field of ecological psychology (Gibson, 1979) and later adopted in design studies (Norman, 1988), Gibson's key insight was that people perceive the environment through its affordances, the possibilities for action it may provide. According to Gibson perspective, the affordances are invariant, and they are always there to be perceived, they do not change as the need of the observer changes. The actor may or may not perceive the affordance, according to his needs (Bucher \& Helmond, 2018). Whereas Norman defines the affordances as " $[\mathrm{t}]$ he perceived and actual properties of the thing, primarily those fundamental properties that determine just how the thing could possibly be used" (Norman, 1988, p. 9). Norman proposes the concept of 'perceived affordance' to suggest the designer should consider that the user should perceive the affordance and it should be visible to be used. However, there are many affordances would be not visible but can also be felt or heard (Bucher \& Helmond, 2018). The concept of affordances (or technology affordances) has been widely used in information and communications technology (ICT), human computer interaction (HCI), and design science studies. Gaver (1991) emphasizes that in affordances we must focus not on technologies or users alone, but also on the fundamental interactions between the two.

Social affordances are "the social structures that take shape in association with a given technical structure" (Postigo, 2016, p. 5).Wang, Wang, and Tang (2018), in their review of application of affordance theory in IS, found that IS scholars should consider social affordances and improve our understanding of IS-related social media use in social processes. Social affordances describe "the relationship between the properties of an object and the social characteristics of a group that enable particular kinds of interactions among members of that group" (Bradner, Kellogg, \& Erickson, 1999). Social affordances include a sense of belonging to a group which may be created through a shared interest or experience (Moreno \& Uhls, 2019). Moreover, social affordances assist people to learn informally by helping them to engage, build social connections, and to be aware of other users' thoughts, opinions and feedback (Ahuja, 2009; Kavanaugh et al., 2012).

Social media is ultimately a technological platform with several features that contain a set of technical and social affordances. Social media provides more advantages than traditional media, the major benefits being interactivity (Al-Sabaawi \& Dahlan, 2018; Alsaadat, 2018; Ersoy \& Güneyli, 2016; Fox \& Ralston, 2016; Genden, 2018; McCarthy, 2015), familiarity (Al-Sabaawi \& Dahlan, 2018; Blaschke, 2014; Genden, 2018), popularity (Garcia et al., 2015), and engagement (Al-Sabaawi \& Dahlan, 2018; McPherson, Budge, \& Lemon, 2015). People tend to use social media for leisure activities (e.g., watching movies) and communication, but many studies confirm that the use of social media has opened new ways of learning. The use of social media as learning tools have increased vastly during the COVID-19 pandemic (Ocaña et al., 2021). Several activities were moved online, and many people have used the potential of social media as a learning resource, while at the same time ensuring that people remain safe and 
healthy online. In informal learning contexts, learners use social media differently based on their needs and therefore each user applies different affordances (Balci, Rosenkranz, \& Schuhen, 2014). The affordances provide a useful lens for studying learning technologies and their impact on human learning (Mao, 2014). In social media studies, the affordance concept has often been used to refer to properties and features of technology only, and fail to pay attention to the social affordances (Costa, 2018). The importance of identifying and perceiving social affordances is yet the same as for technical affordances in socio-technical systems (Pols, 2012). As affordances are never specific to a platform only, but are always specific to the relation between the platform and the situated users (Costa, 2018). This study therefore to provide a descriptive understanding of the social affordances presented to users via social media.

\section{METHODOLOGY}

\subsection{Research Approach}

The main purpose of this study is to identify the social affordances of social media in informal learning. Thus, a qualitative systematic literature review approach is used in this paper which was informed by the Okoli (2015) guidelines for IS researchers. There are five major stages for conducting literature reviews on IS, and they are as follows: (1) Define the protocol, (2) Search the literature, (3) Select the papers, (4) Analyse, synthesise, and interpret the data, (5) Write the review aiming to identify the research gap (Oosterwyk, Brown, \& Geeling, 2019).

\subsection{Research Approach}

In order to identify papers in the field of social media and informal learning, the initial step was to identify papers from IS journals and conferences. Bandara, Furtmueller, Gorbacheva, Miskon, and Beekhuyzen (2015) recommended the use of top-ranked journals and conference papers. These include the Association for Information Systems' (AIS) electronic library and the basket of eight IS journals (European Journal of Information Systems, Information Systems Journal, Information Systems Research, Journal of the Association of Information Systems, Journal of Management Information Systems, MIS Quarterly, Journal of Strategic Information Systems, and Journal of Information Technology) were searched. Fewer papers have been found in IS Journals that focused on social media and informal learning specifically.

Thus, journal articles and conference papers in the field of social media and informal learning were collected from the Web of Science database and Google Scholar, as these databases are frequently used for IS literature reviews (Bandara et al., 2015; Schryen, 2015). Studies and searches included only publications in English from the year 2010 - to date. This period was chosen because going back through ten years of research should be sufficient for IS literature reviews (Oosterwyk et al., 2019; Templier \& Paré, 2015). To identify papers relating to social media and informal learning, the key search terms that were used were specific to the main goal of the study. Key terms used included "informal learning" and "social media." In addition, to track down more literature, we also added "social networking," "web 2.0," and "user-generated content," as keywords in the search (Zeng \& Gerritsen, 2014). This process led to a data corpus of 136 papers which were used for analysis. All papers have been uploaded to EndNote. Okoli (2015) recommended the use of EndNote as a helpful tool to manage references when conducting literature reviews. 


\subsection{Analysis}

Collected papers were exported from EndNote to Excel sheets for analysis. Microsoft Excel is a popular tool for literature reviews and a helpful instrument to analyse papers (Bandara et al., 2015). The data analysis commenced by reviewing each paper's title, topic, abstracts, and keywords. From this initial analysis, the following were identified and removed from the data corpus: book reviews, posters, duplicated papers, and those that did not deal with social media and informal learning. For example, papers such as the "Construction of Informal Learning Knowledge Network Based on Social Network Analysis” by (Ma, Wen, \& Wang, 2019) were removed. After the initial analysis, 55 papers that focused specifically on social media and informal learning remained. The second phase of analysis entailed a careful examination of the remaining papers to identify the social affordances of social media in informal learning contexts. Each paper was examined based on its introductions, conclusions, and main objectives in relation to whether they offered social affordances of social media for informal learning. From the 55 papers, one was omitted on the basis that did not offer social affordances of social media in informal learning contexts. After this second phase, the data corpus stood at 54 papers (see figure 1).

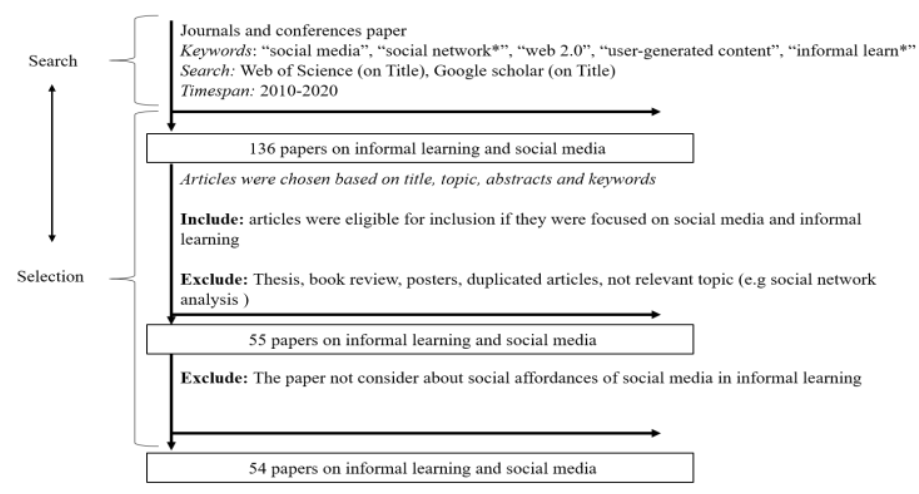

Figure 1. Search and selection process (after the fashion of Günther et al., 2017)

The third phase of analysis involved the use of thematic analysis using NVivo for literature review synthesis to identify social affordances of social media in informal learning environments. NVivo is a qualitative data analysis tool with powerful abilities to analyse, synthesize, and write up IS literature reviews (Bandara et al., 2015; Schryen, 2015). The major themes related to the social affordances of social media for informal learning that emerged from common patterns in the paper corpus, as well as examples of authors are shown in the next section. 


\section{FINDING AND DISSCUSSION}

The purpose of this study was to identify the social affordances of social media in informal learning environments. Following a systematic review process of the articles on social media and informal learning from the peer reviewed papers; the findings identified the following themes as shown in Table 2. These themes are discussed in the following subsections.

\subsection{Interaction}

This study found that more than $80 \%$ of the literature mentioned interaction as a significant social affordance. Informal learners who are willing to use social media for informal learning purposes should interact socially using different social features to achieve their highest learning goals. Interaction is at the core of every virtual community, as it often facilitates a user's need to solve problems and/or learn (Zehrer \& Grabmüller, 2012). Fox and Ralston (2016) in their study refer to interaction affordance as the first phase for learners to start online informal learning in social media environments. Hence, the more learners interact with others, the greater the benefits of using social media platforms for learning. However, not all learners' interactions on social media may lead to achieving learning goals.

\subsection{Engagement}

Social media is about encouraging engagement with other people in a socially interactive environment. From the literature analysis, about $70 \%$ of the research on social media and informal learning point to engagement as one of the main social affordances that allow learners to learn informally. Learners engage with peers in collaborative problem-solving and discussions by liking, commenting, posting questions, and sharing tips on posted topics (Babu, 2015). Also, hashtags, for example, afford people the ability to engage in life-long and life-wide learning processes asynchronously across space and time (Kumar \& Gruzd, 2019). "The type of engagement informal learners have with people on social media depends on their goals. Those who are actively engaged may create more successful communities (Zhang \& Gao, 2014).

\subsection{Sharing}

The majority (85\%) of the publications refer to sharing as an essential social affordance for informal learning. Learners learn when they receive knowledge from others, but they learn more when they share their thoughts, opinions, and information with others. Using social media platforms as informal ways to share their information and experience with one another allows informal learners to become more confident as they can prepare themselves to share their ideas and thoughts without fear of criticism or disapproval (Akpomuje \& Akinsooto, 2016; Fox \& Ralston, 2016; Lisbôa \& Coutinho, 2011; Meace: Sophie, Naamani: Catherine, \& Fiona Carroll, 2018; Wan, Prain, \& Collet, 2014). The affordance of sharing allows users to contribute ideas, resources, articles, photos, videos, ratings, tags, and links (Greenhow \& Lewin, 2016; Islam \& Rabbi, 2016; Yoo \& Kim, 2013). Therefore, the opportunities for learners to share are greater in informal learning environments than in formal learning environments. 


\subsection{Posting}

According to the literature, around $50 \%$ of social media and informal learning papers indicate that posting is a substantial social affordance. Social media afforded posting features as a tool of communication and contacting that allows informal learners to communicate with peers and their teachers anytime and anywhere (Aghili, Palaniappan, Kamali, Aghabozorgi, \& Sardareh, 2014; Sato, Kageto, \& Kirkpatrick, 2013). Learners can post different types of content, such as questions that are answered by others through reply posts and they may also post their photographs and their own educational videos (Fox \& Ralston, 2016; Sato et al., 2013). Heo and Lee (2013) indicate that many learners spend more time creating and managing their own postings and writing their own experiences and thoughts.

\subsection{Participation}

Participation is one of the essential social affordances that were found during the analysing process. Learners participate on social media when they take part in informal learning activities. Participation is also a learning process (Jiménez-Cortés, 2015). Participating is more than sharing with others. Learners can create, refine, and share knowledge, information, and interests through participating with others in social media platforms (Yoo \& Kim, 2013; Zhao \& Kemp, 2012)

\subsection{Discussion}

The analysis of the literature showed that $55 \%$ of papers mention discussion as a way of informal learning through social media platforms. Social media allows learners to have discussions in a relaxed atmosphere with others who have similar interests (Babu, 2015; Kumar \& Gruzd, 2019). In addition, social media is used to facilitate working on projects, as learners discuss project activities online (Sato et al., 2013). However, social media might reveal students' identities to the public and some learners are not aware that their discussions on social media might be publicly available (Chen \& Bryer, 2012). Learners should be able to participate in informal discussions to have their voice heard by others and to gain the maximum learning benefits.

\subsection{Connection}

Around $70 \%$ of the reviewed literature highlighted the importance of having connection. Being connected through social media tools allows users to build communities and to socialize with others. Social media has the ability to maintain social connections and to overcome isolation (Aghili et al., 2014; X. Li, Gray, Verspoor, \& Barnett, 2017; Osborne, 2014). Connecting with people via social media, for the purpose of giving and receiving information, is a way of informal learning (Babu, 2015; Zhao \& Kemp, 2012). Informal learners exchange knowledge through connecting to others by using social media tools, such as Wikipedia, LinkedIn, and WordPress, to name a few; it also connects learners with peers, experts in the field, and communities across the world (Chen \& Bryer, 2012; Fox \& Ralston, 2016). Additionally, social media community members could use hashtag features strategically to connect their messages to a wider topic for more interaction (Lundgren, Crippen, \& Bex, 2020). On other hand, 
IADIS International Journal on WWW/Internet

increasing the number of connections doesn't mean that informal learners are learning efficiently and effectively. Taibi, Gentile, Fulantelli, and Allegra (2010) emphasize that those who use social media informally, should not only to be connected to other people, but that they should be connected to the right people, depending on learner aims.

\subsection{Networking}

Research showed that creating networks or being in a network is a fundamental phase of informal learning on social media. Social media platform tools can be used to promote the development of social learning networks. People connect with others in well-known social media platforms mainly to build their networks with people they may already know, and with strangers based on shared interests (Heo \& Lee, 2013). Social media builds a knowledge network by linking learning resources to a set of competences to be developed, and by connecting people who wish to share, create, and evaluate their knowledge with peers in the network (Zhao \& Kemp, 2012). Learners acquire important network capital by using these technologies and generating collaborative informal learning spaces (Sánchez-Navarro $\&$ Aranda, 2013). However, building networks take time and needs constant learner engagement and social presence while using social media. Social presence is defined as the ability of learners to present themselves as real persons in the online community (Aghili et al., 2014).

\subsection{Communication}

From the research, $76 \%$ of papers provide evidence that social media has been used as a general communication tool. The affordances of communication on social technologies allow users to communicate synchronously or asynchronously, and to maintain social relationships informally and authentically in the virtual environment of the Internet (Dogan, 2014; Heo \& Lee, 2013). For most learners, online communication has become simpler than communicating personally because of the geographical distance between people (Islam \& Rabbi, 2016). Research on social media in learning suggests that integrating social media into learning environments may yield new forms of communication that facilitate knowledge exchange (Greenhow \& Lewin, 2016; Klomsri et al., 2013). Learners can use different social tools, such as texting, microblogging, commenting, liking, skyping, recording, and video conferencing to effectively communicate.

\subsection{Commenting}

The findings show that more than 50\% of the reviewed publications identified comments as major social part of social media. Commenting is a typical social media feature that promotes individual users (Greenhow \& Lewin, 2016), and it can be considered a tool for communication and expression (Michel, Touré, \& Marty, 2018). One of the advantages of using social media for informal learning purposes is the possibility of receiving comments from both friends and non-friends, thus enabling the informal learners to receive multiple perspectives from others (Ab Rashid, Yahaya, Rahman, \& Yunus, 2016; Sato et al., 2013). In addition, learners on social media engage by reading each other's posts and discussions, and answering questions by commenting on posted topics (Babu, 2015; Yoo \& Kim, 2013). Fox and Ralston (2016) indicate that social media allows learners to comment, ask questions, and share things they would not necessarily feel comfortable sharing with learners who know the individuals they are referring 
to. However, the large number of comments, especially those that are irrelevant and negative, can be an issue for informal learners. Learners may miss key instructions and knowledge if it gets lost within too many comments (Sclater, 2016).

\subsection{Collaboration}

About $75 \%$ of reviewed papers mention the collaborative environment provided by social media for informal learners. Informal learners who use social media for learning purposes are not only the consumers but also the producers of the knowledge (Ab Rashid et al., 2016). Learners are using social media as tools to collaborate with their instructors and peers (Dabbagh \& Kitsantas, 2012; Meace: Sophie et al., 2018). Collaboration is a social process and one of the pillars of any learning process. Learners who do not aspire to collaborate with others usually do not complete their informal learning. The affordance of collaboration allows learners to build a knowledge base by commenting for feedback and expressing their thoughts and ideas to each other (Babu, 2015; Zhang \& Gao, 2014).

\subsection{Communities}

The findings indicate that building communities is one of the major social affordances of social media for learning purposes. The sense of belonging to a community is important to enable informal learning processes as informal learners use social media for building appropriate online learning communities (Sato et al., 2013; Zhang \& Gao, 2014). Learning communities are described as groups that have shared interests who communicate informally using social media to achieve their goals (Hamat \& Abu Hassan, 2019). This expands the concept of community of practice $(\mathrm{CoP})$ where people share their knowledge and skills (Bagdy, Dennen, Rutledge, Rowlett, \& Burnick, 2018; Burnick, 2018). CoP has been used as the framework in many studies of social media-based learning. For example, Bagdy et al. (2018) used CoP to explore how teens engage in informal learning via social media.

\subsection{Social-Emotional Affordances}

In the literature we found that there are several social-emotional affordances that have an impact on informal learning processes. Social media is used by learners to deepen their feelings and understanding of the subject and their learning (Meace Sophie, Naamani Catherine, \& Fiona Carroll, 2018). We pointed out some of the social emotional affordances, such as online friendship, identity development, self-expression, and celebrity inspiration.

\subsubsection{Online Friendships}

The need to coexist with others drives people to form relationships with friends. The literature illustrates the importance of learners' socialization with online friends during the informal learning process. Nowadays people of all races, ages, religions, occupations, and socio-economic backgrounds use social media to maintain existing relationships and to make new online friendships (Aghili et al., 2014; Lisbôa \& Coutinho, 2011). Through interaction by chatting and sharing information with online friends, people find ways to learn informally (Akpomuje \& Akinsooto, 2016). Informal learners would prefer to share their thoughts and opinions with their friends on social media as opposed to people they know in real life. The 
affordances of creating friendship on the networking technology allows for quick and rich responses by allowing learners to ask questions online rather than meeting friends face-to-face (Ab Rashid et al., 2016). The more friends are included, the greater the chance for sociability, interaction, possibilities of support, and information acquisition (Sánchez-Navarro \& Aranda, 2013).

\subsubsection{Identity Development}

One in every three papers from previous studies indicated the impact of social media for developing identity. Social media plays a role in identity creation (Melrose, 2012). The learner identity development in an online learning environment is a key feature that prompts the learner on what to share, what not to share, and who to share it with (Dabbagh \& Kitsantas, 2012). Learners in informal learning environments could build their online identity to be whoever they want to be. However, the world of social media is not completely anonymous, as offline relationships can be anchored to online relationships (Barkhordari \& Willemyns, 2016).

\subsubsection{Self-expression}

The findings indicate that informal learners have a tendency to express themselves. The informal nature of social media allows users a space to express themselves in a more relaxed manner (Heo \& Lee, 2013; Sato et al., 2013). By participating in discussions, they engage in positive self-expression that develops their communication skills (Islam \& Rabbi, 2016). Learners' social presence in social media influences their self-expression. Having a social presence on social media enables users to feel comfortable and safe when expressing their ideas, opinions, and points of view (Lisbôa \& Coutinho, 2011).

\subsubsection{Celebrity Inspiration}

Despite many celebrities who use social media, the study found few papers that addressed users following celebrities to learn informally. However, these papers indicate that celebrities inspire learners and have a social-emotional impact on them. Social media is a tool you can use to become a celebrity and it allows celebrities to communicate with followers and to inspire them. Social media users draw inspiration from their heroes' profiles or pages (Islam \& Rabbi, 2016). Informal learners may learn and be uplifted by celebrities on social media (Fox \& Ralston, 2016).

\section{CONCLUSION}

Social media in learning has become the focus of several studies over the last few years (Maria, 2019). However, the analysis of this systematic review found that there are limited papers on social media and informal learning sectors from an IS perspective. Social media provides a variety of affordances. However, social media was not designed for learning purposes specifically. Thus, learners repurpose social media for their informal learning activities to meet their needs. This study sought to identify the social affordances of social media tools in an informal learning context. The findings enumerate thirteen social affordances which users enjoy. These social affordances support informal learning processes that distinguish social media from other applications. Once the perceived social affordances meet the informal learners' goals and needs, they could benefit from social media in their informal learning. Each 
affordance provides users with the agency of feeling they have control of their learning as they contribute towards their learning outcomes. The power shifts from the teacher to the learner giving the learner an active role in their learning. Social affordances identified in this study can therefore be perceived as agency-enabling factors within the social media informal learning context.

However, this agency presupposes the user also has digital agency - "consisting of digital competence, digital confidence and digital accountability - the individual's ability to control and adapt to a digital world" (Passey et al., 2018, p. 425). Possessing digital agency is important, specifically in developing country contexts where there is a lack of digital skills (James, 2019), and implementation of digital technologies in the Higher education sector is slow (Mhlanga \& Moloi, 2020).

For future study there is a need to understand how users perceive and utilize indirect affordances (social affordances). As Norman suggests, affordances will be unused if users fail to perceive an affordance in the first place (Antonenko, Dawson, \& Sahay, 2017). When informal learners fail to perceive the social affordances of social media, this results in failure of informal learning through social media. Then, the social media would be unusable because learners fail to connect the affordances of the social media with their abilities and needs (Antonenko et al., 2017). And we need to understand what are the causes and influences that contribute to the informal leaner either perceiving or not perceiving social affordances during the use of social media.

\section{REFERENCES}

Ab Rashid, R., Yahaya, M. F., Rahman, M. F. A., \& Yunus, K. (2016). Teachers' Informal Learning via Social Networking Technology. International Journal of Emerging Technologies in Learning, 11(10), 76-79. doi:10.3991/ijet.v11i10.5908

Aghili, M., Palaniappan, A. K., Kamali, K., Aghabozorgi, S., \& Sardareh, S. A. (2014). Unifying informal and formal learning environments: Educational use of social network sites through implementing community of inquiry framework. International Journal of e-Education, e-Business, e-Management and e-Learning, 4(3), 191.

Ahuja, S. (2009). A Tale of Two Sites: An explorative study of the design and evaluation of social network sites. Virginia Tech,

Akpomuje, P., \& Akinsooto, T. (2016). Adults' Informal Learning Experiences Using the Social Media in a Nigerian University.

Al-Sabaawi, M. M. Y., \& Dahlan, H. M. (2018). Acceptance Model of Social Media for Informal Learning. Paper presented at the the 2nd International Conference of Reliable Information and Communication Technology (IRICT 2017), Cham.

Alsaadat, K. (2018). The impact of social media technologies on adult learning. International Journal of Electrical and Computer Engineering, 8(5), 3747-3755. doi:10.11591/ijece.v8i5.pp3747-3755

Anderson, C., \& Robey, D. (2017). Affordance potency: Explaining the actualization of technology $\begin{array}{llll}\text { affordances. Information } & \text { Ond } & \text { Organization, } & \end{array}$ doi:https://doi.org/10.1016/j.infoandorg.2017.03.002

Antonenko, P. D., Dawson, K., \& Sahay, S. (2017). A framework for aligning needs, abilities and affordances to inform design and practice of educational technologies. British Journal of Educational Technology, 48(4), 916-927. doi:https://doi.org/10.1111/bjet.12466 
IADIS International Journal on WWW/Internet

Aramo-Immonen, H., Karkkainen, H., Jussila, J. J., Joel-Edgar, S., \& Huhtamaki, J. (2016). Visualizing informal learning behavior from conference participants' Twitter data with the Ostinato Model. Computers in Human Behavior, 55, 584-595. doi:10.1016/j.chb.2015.09.043

Babu, R. (2015). Blind Students' Challenges in Social Media Communication: An Early Investigation of Facebook Usability for Informal Learning. International Journal of Online Pedagogy and Course Design, 5(1), 58-73. doi:10.4018/ijopcd.2015010105

Bagarukayo, E., Ssentamu, P., Mayisela, T., \& Brown, C. (2016). Activity Theory as a Lens to Understand How Facebook Develops Knowledge Application Skills. International Journal of Education and Development using Information and Communication Technology, 12(3), 128.

Bagdy, L. M., Dennen, V. P., Rutledge, S. A., Rowlett, J. T., \& Burnick, S. (2018). Teens and Social Media: A Case Study of High School Students' Informal Learning Practices and Trajectories. Paper presented at the Proceedings of the 9th International Conference on Social Media and Society, Copenhagen, Denmark. https://doi.org/10.1145/3217804.3217920

Balci, B., Rosenkranz, C., \& Schuhen, S. (2014). Identification of different affordances of information technology systems: An empirical study.

Bandara, W., Furtmueller, E., Gorbacheva, E., Miskon, S., \& Beekhuyzen, J. (2015). Achieving Rigor in Literature Reviews: Insights from Qualitative Data Analysis and Tool-Support. Communications of the Association for Information Systems, 37, 154-204. doi:10.17705/1CAIS.03708

Barkhordari, R., \& Willemyns, M. (2016). Young adults' construction of social identity on Facebook: a structural equation model. Paper presented at the 3rd European Conference on Social M di R h Media Research EM Normandie, Caen, France.

Baruh, L., \& Watson, H. (2014). Using Twitter for what? A segmentation study of Twitter usage during Gezi protests. Paper presented at the Proceedings of the European Conference on Social Media.

Betul, C. (2016). Blending Formal and Informal Learning Networks for Online Learning. The International Review of Research in Open and Distributed Learning, 17(3). doi:10.19173/irrodl.v17i3.2344

Blaschke, L. M. (2014). Using social media to engage and develop the online learner in self-determined learning. Research in Learning Technology, 22, 1-23. doi:10.3402/rlt.v22.21635

Bradner, E., Kellogg, W. A., \& Erickson, T. (1999). The Adoption and Use of 'BABBLE': A Field Study of Chat in the Workplace. In S. Bødker, M. Kyng, \& K. Schmidt (Eds.), ECSCW '99: Proceedings of the Sixth European Conference on Computer Supported Cooperative Work 12-16 September 1999, Copenhagen, Denmark (pp. 139-158). Dordrecht: Springer Netherlands.

Bucher, T., \& Helmond, A. (2018). The affordances of social media platforms.

Burnick, L. M. B. V. P. D. S. A. R. J. T. R. S. (2018). Teens and Social Media: A Case Study of High School Students' Informal Learning Practices and Trajectories. Paper presented at the Proceedings of the 9th International Conference on Social Media and Society, Copenhagen, Denmark. https://doi.org/10.1145/3217804.3217920

Chen, B., \& Bryer, T. (2012). Investigating Instructional Strategies for Using Social Media in Formal and Informal Learning. International Review of Research in Open and Distance Learning, 13(1), 87-104. doi:10.19173/irrodl.v13i1.1027

Conner, M. (2012). Learning Through Social Media. In N. M. Seel (Ed.), Encyclopedia of the Sciences of Learning (pp. 1986-1989). Boston, MA: Springer US.

Costa, E. (2018). Affordances-in-practice: An ethnographic critique of social media logic and context collapse. New Media \& Society, 20(10), 3641-3656. doi:10.1177/1461444818756290

Dabbagh, N., \& Kitsantas, A. (2012). Personal Learning Environments, Social Media, and Self-Regulated Learning: A Natural Formula for Connecting Formal and Informal Learning. Internet and Higher Education, 15(1), 3-8. doi:10.1016/j.iheduc.2011.06.002

Dogan, M. E. (2014). Bringing informal communication to the fore in e-learning: Physicians and health educators opinions on using social media for health and healthcare education. Paper presented at the EdMedia + Innovate Learning 2014, Tampere, Finland. https://www.learntechlib.org/p/147816 
Ersoy, M., \& Güneyli, A. (2016). Social Networking as a Tool for Lifelong Learning with Orthopedically Impaired Learners. Journal of Educational Technology \& Society, 19(1), 41-52.

Fayard, A.-L., \& Weeks, J. (2014). Affordances for practice. Information and Organization, 24(4), 236-249. doi:https://doi.org/10.1016/j.infoandorg.2014.10.001

Fox, J., \& Ralston, R. (2016). Queer identity online: Informal learning and teaching experiences of LGBTQ individuals on social media. Computers in Human Behavior, 65, 635-642. doi:10.1016/j.chb.2016.06.009

Garcia, E., Elbeltagi, I. M., Dungay, K., \& Hardaker, G. (2015). Student use of Facebook for informal learning and peer support. International Journal of Information \& Learning Technology, 32(5), 286-299. doi:10.1108/IJILT-09-2015-0024

Gaver, W. W. (1991). Technology affordances. Paper presented at the Proceedings of the SIGCHI Conference on Human Factors in Computing Systems, New Orleans, Louisiana, USA. https://doi.org/10.1145/108844.108856

Genden, S. N. (2018). Informal Learning Through Social Media: Opportunities for Learning Professionals. In M. J. Spector, B. B. Lockee, \& M. D. Childress (Eds.), Learning, Design, and Technology: An International Compendium of Theory, Research, Practice, and Policy (pp. 1-23). Cham: Springer International Publishing.

Gibson, J. (1979). The ecological approach to visual perception. Boston: Houghton Mifling.

Greenhow, C., \& Lewin, C. (2016). Social media and education: reconceptualizing the boundaries of formal and informal learning. Learning, Media and Technology, 41(1), 6-30. doi:10.1080/17439884.2015.1064954

Hamat, A., \& Abu Hassan, H. (2019). Use of Social Media for Informal Language Learning by Malaysian University Students. 3l-Language Linguistics Literature-the Southeast Asian Journal of English Language Studies, 25(4), 68-83. doi:10.17576/31-2019-2504-05

Heo, G. M., \& Lee, R. (2013). Blogs and Social Network Sites as Activity Systems: Exploring Adult Informal Learning Process through Activity Theory Framework. Educational Technology \& Society, 16(4), 133-145. Retrieved from <Go to ISI >://WOS:000327764400011

Hsi, S. (2015). Technology for Informal and Out-of-School Learning of Science. In R. Gunstone (Ed.), Encyclopedia of Science Education (pp. 1053-1055). Dordrecht: Springer Netherlands.

Islam, R., \& Rabbi, F. (2016). Researching Students' Experience of Social Media Use as an Informal Learning Platform. Paper presented at the International Confernece on Teaching and Learning (ICTL).

James, J. (2019). Confronting the scarcity of digital skills among the poor in developing countries. Development Policy Review, 39(2), 324-339. doi:https://doi.org/10.1111/dpr.12479

Jiménez-Cortés, R. (2015). The influence of informal learning processes of social network sites on the subjective well-being of women in rural areas / La influencia de procesos de aprendizaje informal en las redes sociales digitales en el bienestar subjetivo de mujeres de zonas rurales. Culture and Education, 27(2), 407-439. doi:10.1080/11356405.2015.1034534

Kalantzis, M., \& Cope, B. (2015). Learning and new media. The Sage handbook of learning, 373-387.

Kanwar, A. S., Balasubramanian, K., \& Umar, A. (2013). Lifelong learning in South Africa. International Journal of Continuing Education \& Lifelong Learning, 5(2), 17-39.

Kavanaugh, A., Gad, S., Neidig, S., Pérez-Quiñones, M. A., Tedesco, J., Ahuja, A., \& Ramakrishnan, N. (2012). (Hyper) local news aggregation: designing for social affordances. Paper presented at the Proceedings of the 13th Annual International Conference on Digital Government Research, College Park, Maryland, USA. https://doi.org/10.1145/2307729.2307736

Klomsri, T., Grebäck, L., \& Tedre, M. (2013). Social media in everyday learning: How Facebook supports informal learning among young adults in South Africa. Paper presented at the Proceedings of the 13th Koli Calling International Conference on Computing Education Research.

Kumar, P., \& Gruzd, A. (2019). Social Media for Informal Learning: a Case of\# Twitterstorians. Paper presented at the Proceedings of the 52nd Hawaii International Conference on System Sciences. 
IADIS International Journal on WWW/Internet

Lay Shi, N., Siew Ming, T., \& Noorizah Mohd, N. (2018). The Usage of Social Networking Sites for Informal Learning: A Comparative Study Between Malaysia Students of Different Gender and Age Group. International Journal of Computer-Assisted Language Learning and Teaching (IJCALLT), 8(4), 76-88. doi:10.4018/IJCALLT.2018100106

Li, X., Gray, K., Verspoor, K., \& Barnett, S. (2017). Understanding the context of learning in an online social network for health professionals' informal learning. Studies In Health Technology And Informatics, 235, 353-357.

Li, Y. (2013). Informal learning in the Web 2.0 environment: how Chinese students who are learning English use Web 2.0 tools for informal learning.

Lisbôa, E. S., \& Coutinho, C. P. (2011). Informal learning in social networks: A study of the Orkut social network. Issues in Educational Research, 21(2), 162.

Lundgren, L., Crippen, K. J., \& Bex, R. T. (2020). Social Media Interaction as Informal Science Learning: a Comparison of Message Design in Two Niches. Research in Science Education. doi:10.1007/s11165019-09911-y

Ma, Y., Wen, B., \& Wang, J. (2019). Construction of Informal Learning Knowledge Network Based on Social Network Analysis. Paper presented at the 2019 IEEE International Conference on Computer Science and Educational Informatization (CSEI).

Majchrzak, A., Faraj, S., Kane, G. C., \& Azad, B. (2013). The contradictory influence of social media affordances on online communal knowledge sharing. Journal of Computer-Mediated Communication, 19(1), 38-55.

Mao, J. (2014). Social media for learning: A mixed methods study on high school students' technology affordances and perspectives. Computers in Human Behavior, 33, 213-223. doi:https://doi.org/10.1016/j.chb.2014.01.002

Maria, R. (2019). Professional development in the digital age. Benefits and constraints of social media for lifelong learning. Form @ re - Open Journal per la formazione in rete, 19(2). doi:10.13128/formare25353

McCarthy, J. (2015). Learning in the "Café": Pilot Testing the Collaborative Application for Education in Facebook. Australasian Journal of Educational Technology, 31(1), 67-85. doi:10.14742/ajet.1500

McPherson, M., Budge, K., \& Lemon, N. (2015). New Practices in Doing Academic Development: Twitter as an Informal Learning Space. International Journal for Academic Development, 20(2), 126-136.

Melrose, P. (2012). Irish Students and Facebook: Informal learning choices in a Web 2.0 world. Irish Journal of Academic Practice, 1(1), 5.

Mhlanga, D., \& Moloi, T. (2020). COVID-19 and the Digital Transformation of Education: What Are We Learning on 4IR in South Africa? Education Sciences, 10(7), 180. Retrieved from https://www.mdpi.com/2227-7102/10/7/180

Michel, C., Touré, C., \& Marty, J.-C. (2018). Adapting Enterprise Social Media for Informal Learning in the Workplace: Using Incremental and Iterative Design Methods to Favor Sustainable Uses. Paper presented at the International Conference on Computer Supported Education, Cham.

Moreno, M. A., \& Uhls, Y. T. (2019). Applying an affordances approach and a developmental lens to approach adolescent social media use. DIGITAL HEALTH, 5, 2055207619826678. doi: $10.1177 / 2055207619826678$

Norman, D. A. (1988). The psychology of everyday things: Basic books.

Ocaña, M., Mejía, R., Larrea, C., Analuisa, C., \& Freire, C. (2021). Informal Learning in Social Networks During the COVID-19 Pandemic: An Empirical Analysis. Artificial Intelligence, Computer and Software Engineering AdvancesProceedings of the CIT 2020 Volume 2, 1327, 400-414.

Okoli, C. (2015). A Guide to Conducting a Standalone Systematic Literature Review. Communications of the Association for Information Systems, 37. doi:10.17705/1CAIS.03743 
Oosterwyk, G., Brown, I., \& Geeling, S. (2019). A Synthesis of Literature Review Guidelines from Information Systems Journals. Paper presented at the Proceedings of 4th International Conference on the.

Osborne, N. (2014). Learning from others mistakes: how social media etiquette distorts informal learning online. Paper presented at the Proceedings of the European Conference on Social Media.

Palmieri, R., \& Giglio, C. (2015). Informal Learning in Online Social Network Environments: An Evidence from an Academic Community on Facebook. The Turkish Online Journal of Educational Technology.

Passey, D., Shonfeld, M., Appleby, L., Judge, M., Saito, T., \& Smits, A. (2018). Digital Agency: Empowering Equity in and through Education. Technology, Knowledge and Learning, 23(3), 425-439. doi:10.1007/s10758-018-9384-x

Pols, A. J. K. (2012). Characterising affordances: The descriptions-of-affordances-model. Design Studies, 33(2), 113-125. doi:https://doi.org/10.1016/j.destud.2011.07.007

Postigo, H. (2016). The socio-technical architecture of digital labor: Converting play into YouTube money. New Media \& Society, 18(2), 332-349. doi:10.1177/1461444814541527

Pozzi, G., Pigni, F., \& Vitari, C. (2014). Affordance Theory in the IS Discipline: a Review and Synthesis of the Literature.

Sánchez-Navarro, J., \& Aranda, D. (2013). Messenger and social network sites as tools for sociability, leisure and informal learning for Spanish young people. European Journal of Communication, 28(1), 67-75.

Sangrà, A., \& Wheeler, S. (2013). New Informal Ways of Learning: Or Are We Formalising the Informal? RUSC, 10(1), 286-293.

Sato, S., Kageto, M., \& Kirkpatrick, G. (2013). Analysis of informal use of social media in forma project-based learning. International Journal for Educational Media and Technology, 7(1), 26-37.

Schryen, G. (2015). Writing qualitative IS literature reviews - Guidelines for synthesis, interpretation and guidance of research. Communications of the AIS, 37, 286-325. doi:10.17705/1CAIS.03712

Sclater, N. (2016). MOOCs, Open educational resources and social networking: bridging the gap between informal and formal learning. Revista Mediterranea Comunicacion-Journal of Communication, 7(2), 9-19. doi:10.14198/medcom2016.7.2.1

Sophie, M., Catherine, N., \& Carroll, F. (2018). Building the 'Connection'Between the Student, their Peers and the Lecturer: How Social Media can Enhance Student Engagement and Afford Informal Learning Opportunities.

Sophie, M., Catherine, N., \& Carroll, F. (2018). Building the 'Connection'Between the Student, their Peers and the Lecturer: How Social Media can Enhance Student Engagement and Afford Informal Learning Opportunities. Paper presented at the 10th International Conference on Education and New Learning Technologies.

Stendal, K., Thapa, D., \& Lanamäki, A. (2016). Analyzing the concept of affordances in information systems. Paper presented at the 2016 49th Hawaii International Conference on System Sciences (HICSS).

Taibi, D., Gentile, M., Fulantelli, G., \& Allegra, M. (2010). An Ontology to Model e-portfolio and Social Relationship in Web 2.0 Informal Learning Environments. International Journal of Computers Communications \& Control, 5(4), 578-585. doi:10.15837/ijccc.2010.4.2516

Tallent, G. (2014). The Social Media Canvas and Its Use in Strategy Formulation. Paper presented at the European Conference on Social Media.

Templier, M., \& Paré, G. J. C. o. t. A. f. I. S. (2015). A framework for guiding and evaluating literature reviews. 37(1), 6 .

Van Osch, W., \& Mendelson, O. (2011). A typology of affordances: Untangling sociomaterial interactions through video analysis. 
IADIS International Journal on WWW/Internet

Volkoff, O., \& Strong, D. M. (2017). Affordance theory and how to use it in IS research. In The Routledge companion to management information systems (pp. 232-245): Routledge.

Wan, C. W. I. R. C., Prain, V., \& Collet, P. (2014). Perceived learning strategies of Malaysian university students in Web 2.0-based English as a Second Language informal learning. GEMA Online ${ }^{\circledR}$ Journal of Language Studies, 14(1).

Wang, H., Wang, J., \& Tang, Q. (2018). A Review of Application of Affordance Theory in Information Systems. 11(1), 56-70

Yakin, I., \& Gencel, I. E. (2013). The Utilization of Social Media Tools for Informal Learning Activities: A Survey Study. Mevlana International Journal of Education, 3(4), 108.

Yoo, S., \& Kim, S. (2013). How and why college students use Web 2.0 applications: The role of social media in formal and informal learning. Int. J. of Web Based Communities, 9, 174-187. doi:10.1504/IJWBC.2013.053242

Zehrer, A., \& Grabmüller, A. (2012). Social media marketing in tourism education:Insights into the development and value of a social network site for a higher education institution in tourism. $18(3)$, 221-228. doi:10.1177/1356766712449368

Zeng, B., \& Gerritsen, R. (2014). What do we know about social media in tourism? A review. Tourism Management Perspectives, 10, 27-36. doi:https://doi.org/10.1016/j.tmp.2014.01.001

Zhang, K., \& Gao, F. (2014). Social media for informal science learning in China: A case study. Knowledge Management \& E-Learning: An International Journal, 6(3), 262-280.

Zhao, F., \& Kemp, L. (2012). Integrating Web 2.0-based informal learning with workplace training. Educational Media International, 49(3), 231-245. doi:10.1080/09523987.2012.738015 